\title{
Identificação de solos expansivos e colapsíveis no Nordeste brasileiro a partir de Redes Neurais Artificiais geradas em Pernambuco
}

\author{
Identification of expansive and collapsible soils in northeastern Brazil from Artificial Neural \\ Networks generated in Pernambuco \\ Identificación de suelos expansivos y colapsables en el noreste de Brasil a partir de Redes \\ Neuronales Artificiales generadas en Pernambuco
}

Recebido: 29/10/2021 | Revisado: 08/11/2021 | Aceito: 12/11/2021 | Publicado: 21/11/2021

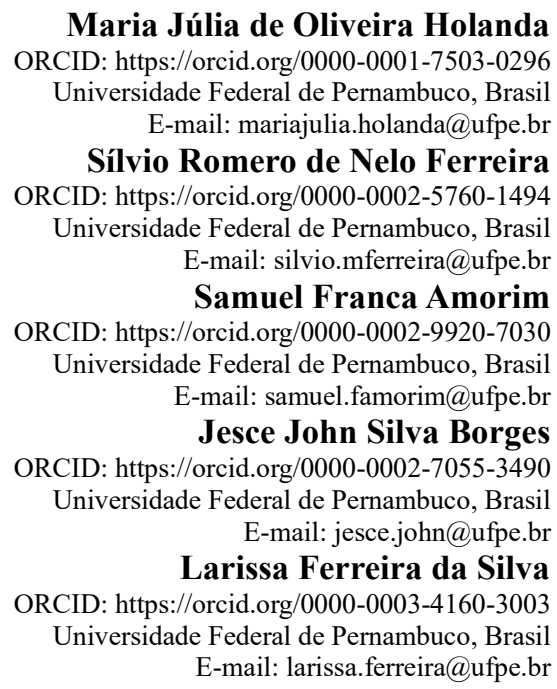

\begin{abstract}
Resumo
Solos colapsíveis e expansivos são problemáticos na Engenharia Civil causando patologias nas edificações devido à variação de volume com a mudança de umidade. A identificação desses solos na fase de projeto é importante. $\mathrm{O}$ artigo visa elaborar uma arquitetura de Rede Neural Artificial treinada com solos de Pernambuco, para identificação de solos expansivos e colapsíveis, e ampliar sua aplicação à solos dos demais estados do Nordeste brasileiro. Desenvolvida a partir de 87 amostras, divididas entre grupos de treinamento (53 amostras), seleção (17 amostras) e teste (17 amostras), segundo 4 variáveis de entrada porcentagem de areia, porcentagem de argila, índices de plasticidade e atividade. A melhor arquitetura da rede consiste em 4 neurônios na entrada e 1 na saída. Para a validação às cegas do modelo, a rede foi aplicada a 45 amostras de solos colapsíveis e expansivos de demais estados do Nordeste. A análise de desempenho da precisão de classificação da rede com dados de Pernambuco apresentou uma taxa de acurácia de $76,5 \%$ e na validação nos demais estados do Nordeste o reconhecimento de padrões foi ainda maior, atingindo acurácia de $91,1 \%$, demonstrando capacidade de capturar tendências no movimento da superfície do solo e auxiliando na resolução de problemas.
\end{abstract}

Palavras-chave: Solos expansivos; Solos colapsíveis; Redes neurais artificiais; Equação de classificação.

\begin{abstract}
Collapsible and expansive soils are problematic in Civil Engineering, causing pathologies in buildings due to the variation in volume with the change in humidity. The identification of these soils in the design phase is important. The paper aims to develop an Artificial Neural Network architecture trained with soils from Pernambuco, to identify expansive and collapsible soils, and expand its application to soils from other states in Northeastern Brazil. Developed from 87 samples, divided between training (53 samples), selection (17 samples) and test (17 samples) groups, according to 4 input variables, percentage of sand, percentage of clay, plasticity and activity indices. The best network architecture consists of 4 neurons at the input and 1 at the output. For the blind validation of the model, the network was applied to 45 samples of collapsible and expansive soils from other Northeastern states. The performance analysis of the classification accuracy of the network with data from Pernambuco showed an accuracy rate of $76.5 \%$ and in the
\end{abstract}


validation in the other Northeastern states, pattern recognition was even higher, reaching an accuracy of $91.1 \%$, demonstrating capacity capturing trends in soil surface movement and aiding in problem solving.

Keywords: Expansive soils; Collapsible soils; Artificial neural networks; Classification equation.

\section{Resumen}

Los suelos colapsables y expansivos son problemáticos en la Ingeniería Civil, provocando patologías en los edificios debido a la variación de volumen con el cambio de humedad. La identificación de estos suelos en la fase de diseño es importante. El artículo tiene como objetivo desarrollar una arquitectura de Red Neural Artificial entrenada con suelos de Pernambuco, para identificar suelos expansivos y colapsables, y ampliar su aplicación a suelos de otros estados del noreste de Brasil. Desarrollado a partir de 87 muestras, divididas entre los grupos de entrenamiento (53 muestras), selección (17 muestras) y prueba (17 muestras), según 4 variables de entrada, porcentaje de arena, porcentaje de arcilla, índices de plasticidad y actividad. La mejor arquitectura de red consta de 4 neuronas en la entrada y 1 en la salida. Para la validación ciega del modelo, se aplicó la red a 45 muestras de suelos colapsables y expansivos de otros estados del Noreste. El análisis de desempeño de la precisión de clasificación de la red con datos de Pernambuco arrojó una tasa de precisión del $76.5 \%$ y en la validación en los otros estados del Noreste, el reconocimiento de patrones fue aún mayor, alcanzando una precisión del $91.1 \%$, demostrando capacidad de captura de tendencias en el movimiento de la superficie del suelo y ayudar en la resolución de problemas.

Palabras clave: Suelos expansivos; Suelos colapsables; Redes neuronales artificiales; Ecuación de clasificación.

\section{Introdução}

Muitos edifícios, estruturas leves, rodovias, ferrovias, canais, tubulações, muros de contenção de terra, represas e pontes são levados à ruína por solos colapsíveis e expansivos (Simões de Oliveira, Jesus \& Miranda, 2006; Nakashima, Saito \& Hella, 2014). Nesses casos, tensões podem ser criadas, diminuindo ou aumentando rapidamente, quando ocorrem alterações de umidade, provocando mudanças de volume. Tendo em vista o uso e ocupação do solo por obras civis, é recomendado que o solo seja avaliado quanto à expansão e colapso sempre que esse seja considerado não saturado e inserido em um local propício à ocorrência.

Os solos colapsíveis, geralmente compostos de minerais estáveis em presença de água como caulinita e quartzo, tem a condição de colapsividade favorecida quando tais minerais ou agregados de minerais são ligados por compostos químicos solúveis, como os sais (Gitirana Junior et al., 2012). Esse comportamento se caracteriza por ser muito rápido e capaz de provocar sérios danos em construções, especialmente as de pequeno porte em que as pressões de trabalho nas fundações variam entre 100 e $200 \mathrm{kPa}$ (Teixeira, 1998).

As regiões tropicais oferecem condições propícias para a formação de solos colapsíveis. No Brasil, a ocorrência está localizada, principalmente, nas regiões do Centro-sul, Nordeste e grande parte do Sudeste, onde existe o maior número de estudos científicos (Bandeira, Souza Neto \& Rolim, 2017; Paiva et al., 2012; Ferreira, 1990). Na maior parte são solos porosos tropicais, especialmente oriundos de rochas graníticas e outras rochas ácidas, depósitos aluviais, coluviais e residuais muito lixiviados. Mesmo considerando que as perdas decorrentes desse processo tenham um caráter eminentemente econômico, sua quantificação, caso efetuada, proporciona resultados expressivos, dada a grande disseminação espacial do problema (Rodrigues \& Vilar, 2013).

Nos solos expansivos a instabilidade é mais relevante com a presença de argilominerais vermiculitas e montmorilonitas. Há outros fatores relacionados ao solo como distribuição das partículas de argila, porosidade, orientação mineralógica, perfil estratigráfico e espessura do solo, que atuam de modo secundário no potencial expansivo (Nelson \& Miller, 1992; Driscoll \& Crilly, 2000). No Brasil, embora não haja relatos de custos provenientes de danos por solos expansivos, a ocorrência desses solos é identificada em todas as regiões do país (Sobral, 1956; Simmes \& Costa Filho, 1981; Vargas, 1981; Jucá, Gusmão Filho \& Justino da Silva, 1992; Ferreira \& Ferreira, 2009; Paiva et al. (2012); Suleiman, Tapahuasco \& Neto, 2013; Paiva et al., 2016).

Bandeira, Souza Neto \& Rolim (2017) destacam que para a elaboração de um projeto de fundações em solos não saturados, estudos sobre expansibilidade e colapsibilidade são imprescindíveis. O desempenho das fundações e estruturas de obras em solos expansivos ou colapsíveis é associado a limites de Atterberg e a porcentagem de solo passante na peneira $\mathrm{n}^{\circ} 200$ (American Society for Testing and Materials - ASTM), segundo levantamentos feitos por engenheiros geotécnicos em pesquisas 
de mestrado, doutorado e artigos nacionais e internacionais, dando origem assim ao Banco de Dados de Solos Especiais (BANDASE) iniciado por Ferreira (1990). Tal pesquisa resultou no mapa de inventário de ocorrências, que quando comparado às cartas de suscetibilidade de solos colapsíveis e expansivos, evidencia a concomitância dessas ocorrências com áreas definidas com médio-alto potencial de inchamento.

As Redes Neurais Artificiais (RNA), além de outras aplicações, são excelentes mecanismos computacionais que, com base no aprendizado neural biológico, e a partir da análise de um banco de dados, podem realizar previsões, classificações, reconhecimento de padrões e aproximações de funções (Pessoa et al., 2021). Trabalhos como os de Basma, Barakat \& Omar (2003), Moosavi Yazdanpanah \& Doostmohammadi (2006) e Doris, Rizzo \& Dewoolkar (2008), Ashayeri \& Yasrebi (2009), Ikizler et al. (2010) e Merouane \& Mamoune (2018) desenvolveram RNA para capturar tendências no movimento vertical da superfície do solo e prever a porcentagem de expansão livre e a tensão de expansão de solo, comparando a relação entre os valores de tensões medidos e os valores obtidos pelas RNA, todas essas pesquisas alcançaram percentuais acima de $90 \%$ de correlação na previsão.

A aplicação de RNA para identificação de solos colapsíveis e expansivos pode reduzir o número de ensaios direto durante a fase de reconhecimento do terreno, diminuindo o tempo de investigação nessa etapa; se comparado com métodos estatísticos. Isso possibilita identificar um solo com potencial expansivo ou colapsível utilizando condicionantes geotécnicos por meio de RNA.

O presente artigo visa desenvolver uma RNA treinada com dados de solos expansivos e colapsíveis de Pernambuco e ampliar sua aplicação, numa validação às cegas analisando o potencial de sua exportação com a previsão de identificação e classificação da expansão e colapso, aos solos dos demais estados do Nordeste brasileiro.

\section{Metodologia}

A metodologia adotada neste trabalho é predominantemente estruturalista de acordo com Pereira et al. (2018). A pesquisa é estabelecida com a investigação de um evento factual, em seguida, amplia-se para a abstração do plano pelo projeto de modelos computacionais, a partir do banco de dados de amostras de solos, desenvolvido pelo Grupo de Pesquisa de Solos Não-Saturados (GNSAT) da Universidade Federal de Pernambuco (UFPE), o BANDASE (Ferreira, 1990); dessa forma, representa-se o propósito científico e, por fim, mostra-se o resultado da investigação, vinculado a informações a priori sobre a realidade, idealizadas e correlacionadas às condições e restrições sociais, ambientais e econômicas (Pereira et al., 2018). O estudo tem caráter quantitativo, no qual realizou-se pesquisa bibliográfica a fim do levantamento e análise de dados por meio de técnicas matemáticas como é o caso das porcentagens, estatísticas e/ou probabilidades, métodos numéricos, métodos analíticos e geração de equações e/ou fórmulas matemáticas aplicáveis ao processo, possibilitando a previsão dos acontecimentos.

Para o desenvolvimento (treinamento, seleção e testes) da rede neural foram usadas 87 amostras de solos expansivos e colapsíveis do estado de Pernambuco, enquanto outras 45 amostras de solos expansivos e colapsíveis, provenientes das mais variadas áreas do Nordeste brasileiro, foram reservadas para a validação às cegas da RNA.

O banco de dados de amostras de solos que compõem essa pesquisa faz parte do trabalho desenvolvido pelo Grupo de Pesquisa de Solos Não-Saturados (GÑSAT) da Universidade Federal de Pernambuco (UFPE), o BANDASE (Ferreira, 1990). Para o desenvolvimento (treinamento, seleção e testes) da rede neural foram usadas 87 amostras de solos expansivos e colapsíveis do estado de Pernambuco, enquanto outras 45 amostras de solos expansivos e colapsíveis, provenientes das mais variadas áreas do Nordeste brasileiro, foram reservadas para a validação às cegas da RNA.

As amostras do banco de dados para treinamento e validação às cegas da rede (87 amostras de Pernambuco e as 45 amostras dos demais estados do Nordeste, respectivamente) são identificadas na ilustração abaixo segundo os critérios qualitativos de Skempton (1953), Figura 1(a); Van Der Merve (1964), Figura 1(b) e Daksanamurthy \& Raman (1973), Figura 
1(c), considerando os seguintes índices: limite de liquidez, índice de plasticidade, $\%$ de solo $<2 \mu \mathrm{m}$, umidade e sucção, a fim de observar a congruência entre as regiões.

Figura 1 - Critérios comumente utilizados no mundo para determinar o potencial de expansão: (a) Skempton (1953), (b) Van Der Merve (1964) e (c) Daksanamurthy e Raman (1973), aplicados aos solos de Pernambuco e demais estados do Nordeste.
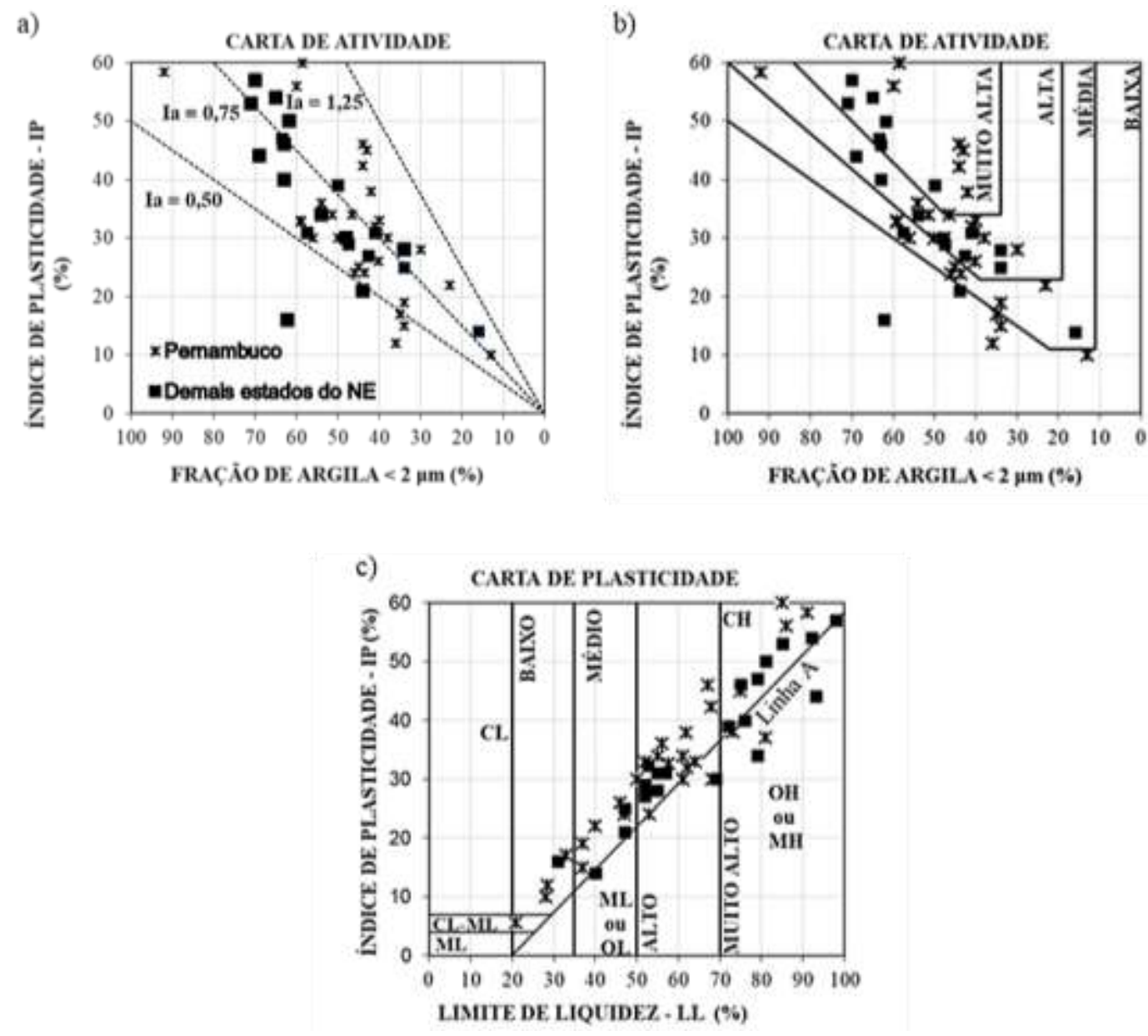

Fonte: Autores (2021).

Os resultados do grau de atividade para os solos de Pernambuco, pelo Critério de Skempton (1953), apresentou que 33,3\% deles são Inativos, 35,9\% Normais e 30,8\% Ativos; enquanto para Van Der Merve (1964), tem-se 17,9\% Muito Alta, 25,6\% Alta, 20,5\% Média e 35,9\% Baixa atividade. Os solos de Pernambuco tiveram 15,6\% Muito Alta plasticidade, 51,1\% Alta, 20\% Média e 13,3\% Baixa, segundo Daksanamurthy e Raman (1973). Neste artigo, as amostras de solos localizadas nas mesmas coordenadas geográficas, mas a diferentes profundidades, são consideradas como pontos diferentes na coleta de dados.

Para a seleção das variáveis de entrada foram considerados fatores que influenciam significativamente no potencial de expansão dos solos, segundo os trabalhos de Ferreira (1990), Basma, Barakat \& Omar (2003), Moosavi Yazdanpanah \& Doostmohammadi (2006) e Doris, Rizzo \& Dewoolkar (2008), Ashayeri \& Yasrebi (2009), Ikizler et al. (2010) e Merouane \& Mamoune (2018); e dos critérios geotécnicos acima mencionados, apontando variáveis de baixo custo e fácil obtenção em ensaios comuns de caracterização do solo e de baixo custo. A análise estatística, aplicada às variáveis de entrada propostas pela revisão bibliográfica, é baseada na dispersão de índices, que possuem coeficientes de variação entre os dados de entrada distantes de zero e próximos a 1 e -1 (análise de componentes principais). Assim, quatro índices de identificação geotécnica foram considerados: fração do solo de argila e de areia, índice de plasticidade e índice de atividade. 
O algoritmo do programa utilizado para formação dos grupos de dados de entrada extrai automaticamente combinações no conjunto de dados que fornecem a melhor generalização, através de um subconjunto de entradas que minimiza o erro de seleção, para esse caso usou-se o método estocástico do algoritmo genético. Após a definição dessas 4 variáveis de entrada e dos grupos de treinamento, seleção e teste, ocorre o desenvolvimento da rede neural com a representação da melhor arquitetura que a defina, e por fim, é verificado o resultado dos testes de desempenho a partir das análises da matriz de confusão e parâmetros derivados, do gráfico ROC e do gráfico de ganho acumulado.

A RNA é capaz de trabalhar com casos de amostras, que por algum motivo, tem registros de entrada ausentes, essas entradas, comuns em bancos de dados construídos a partir de diversas fontes, são representadas por símbolos no conjunto de dados, alguns como: 'NA' (não disponível), 'NaN” (não é um número), 'Desconhecido' ou '?'. Valores numéricos (como zero) não devem ser usados para representar a ausência de informações, de modo a evitar o equívoco entre informações ausentes e valores verdadeiramente nulos.

\section{Desenvolvimento da Rede Neural de Solos Expansivos e Colapsíveis do Estado de Pernambuco}

A RNA aplicada aos solos expansivos e colapsíveis do estado de Pernambuco foi desenvolvida através do Neural Designer (4.2.0), uma plataforma de análise de dados que permite criar, treinar e implantar modelos de redes neurais, para estabelecer padrões consistentes, através de três etapas: Treinamento (aprendizagem), Seleção (arquitetura da rede) e Testes (comparar as saídas da rede neural em um conjunto de variáveis independentes, por meio da Matriz de Confusão e suas métricas de avaliação binária, área estabelecida pela curva ROC e pelo percentual de ganho acumulado na identificação de amostras expansivas).

A Figura 2, mostra a análise de componentes principais, onde verifica-se que há uma forte relação direta entre a fração de Argila e IP, enquanto a relação entre a fração de Areia e IP e a fração de Areia e a fração de Argila apresentam-se ainda fortes, mas de forma inversa; confirmando que a presença de Areia diminui o IP e a fração Argila e consequentemente a suscetibilidade a expansão. O dimensionamento da camada de entrada da rede neural foi feito com base no Desvio Padrão Médio. A Figura 3, apresenta os valores de correlação entre todas as entradas e a saída, obtidos pelo treinamento da RNA. Correlações próximas de 1 significam que uma única saída está correlacionada com uma única entrada. Correlações próximas de 0 significam que não há um relacionamento entre a entrada e a variável de saída. Em geral, as saídas dependem de muitas entradas simultaneamente.

A partir dessas correlações, a etapa de escolha da melhor arquitetura foi definida por meio do algoritmo de seleção de neurônios, usado para encontrar a complexidade da rede neural que produz as melhores propriedades de generalização. Quanto maior o número de neurônios ocultos, menor o erro de treinamento, porém, para pequenas e grandes complexidades, o erro de seleção é significativo, o que implicaria em situações de underfitting e overfitting, respectivamente. Assim, o algoritmo começa com um pequeno número de neurônios e aumenta a complexidade da arquitetura até que os critérios de parada sejam atendidos, retornando a rede neural com o número ideal de neurônios ativados pela função logística. 
Figura 2 - a) Correlações entre as variáveis de entrada (análise de componentes principais). b) Correlações entre as variáveis de entrada e variável de destino.

a)

\begin{tabular}{|c|r|r|r|r|}
\hline & Argila & Areia & \multicolumn{1}{c|}{ IP } & \multicolumn{1}{c|}{ IA } \\
\hline Argila & 1 & $-0,84$ & 0,83 & $-0,23$ \\
\hline Areia & & 1 & $-0,76$ & 0,11 \\
\hline IP & & & 1 & 0,25 \\
\hline IA & & & & 1 \\
\hline
\end{tabular}

b)

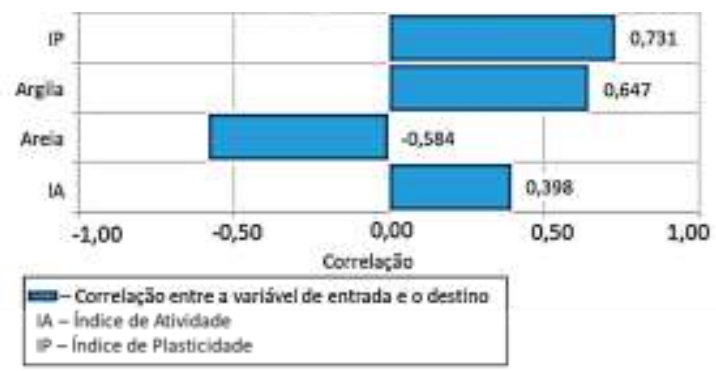

Fonte: Autores (2021)

As correlações obtidas na Figura 2 ratificam a aplicabilidade de tais variáveis de entrada, segundo Seed, Woodward \& Lundgren (1962) índices físicos como porcentagem da fração do solo e índice de atividade são fortes indicadores de comportamento colapsível e expansivo, e ainda de acordo com Chen (1975) o Índice de Plasticidade é diretamente proporcional a expansividade dos solos, enquanto o percentual de Areia tem sua correlação inversa. A Tabela 1 apresenta a estatística descritiva das variáveis de entrada e de saída que compõem a RNA.

Tabela 1 - Estatística Descritiva das variáveis de entrada e da variável de saída que compõem a Rede Neural.

\begin{tabular}{llllll}
\hline Variáveis & Mínimo & Máximo & Média & Desvio Padrão & Variância \\
\hline \% Argila & 2,10 & 94,00 & 31,31 & 20,73 & 424,70 \\
\% Areia & 3,00 & 94,00 & 47,66 & 25,73 & 654,25 \\
IP & 2,00 & 60,00 & 20,69 & 14,05 & 194,56 \\
IA & 0,11 & 2,75 & 0,66 & 0,42 & 0,18 \\
Expansão (saída) & 0,00 & 1,00 & 0,53 & 0,50 & 0,25 \\
\hline
\end{tabular}

Fonte: Autores (2021).

É importante dimensionar as proporções de distribuição das amostras para que todas tenham um intervalo equivalente, o dimensionamento do Neural Designer é feito a partir de algumas estatísticas básicas sobre as entradas, Tabela 1, que incluem a média, o desvio padrão, os valores mínimo e máximo e a variância das amostras. Para a situação em questão, tem-se que valores de Desvio Padrão e Variância altos representam uma maior heterogeneidade desses dados, o que acarreta uma maior variabilidade das características de \% de Argila, \% de Areia e IP das amostras do banco de dados, isso proporciona à rede um maior Aprendizado. À proporção que apresentou o melhor resultado de distribuição das amostras nas 3 etapas foi 61\% (53) treinamento, 19,5\% (17) seleção e 19,5\% (17) teste. A distribuição dos dados deve ocorrer de maneira uniforme e aleatória, para que a rede possa identificar ambas as situações (expansivo ou colapsível). Esta amostragem foge de abordagens mais clássicas (Haykin, 1994; Prechelt, 1997) de 50\% (treinamento) 25\% (validação) e 25\% (teste) porém foi otimizada para um melhor desempenho.

Durante a etapa de treinamento do sistema de classificação binária, vários modelos com arquiteturas diferentes tiveram seus desempenhos comparados e o melhor padrão de generalização, teve suas amostras separadas em grupos para as etapas seguintes (seleção e teste), para a não repetição das amostras em etapas diferentes. Nessa etapa de treinamento, prezou-se por amostras que tivessem um máximo de 2 informações das variáveis de entrada ausentes, de modo que assim a rede tivesse um maior aprendizado das características, ainda que com um banco de dados reduzido. 
A etapa de seleção define a arquitetura da rede que desempenha a melhor generalização, segundo a seleção de ordem e de entradas. A arquitetura ideal definida para a rede, Figura 3, conta com 4 variáveis de entrada (círculos pretos), uma camada de escala para normalização das variáveis de entrada (círculos amarelos), duas camadas perceptron ou rede neural propriamente dita (círculos azuis), que têm seus neurônios ativados pela função logística devido à característica binária das variáveis de saída e a função esperada da rede de classificação, e uma camada probabilística para que a saída tenha sentido de probabilidade de ocorrência (círculo vermelho).

Figura 3 - Arquitetura da Rede.

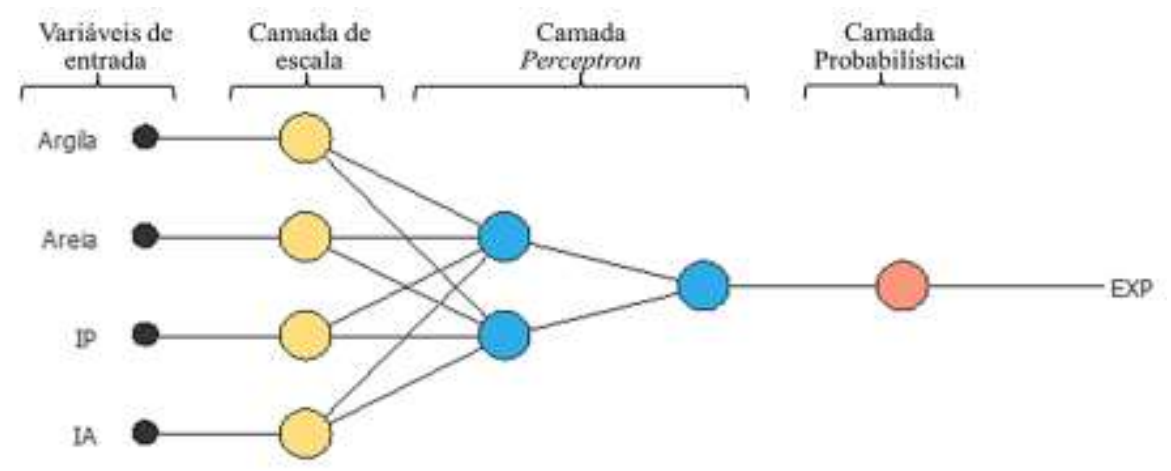

Fonte: Autores (2021).

A definição dos ajustes necessários à etapa de seleção é feita segundo as características do banco de dados utilizado, bem como as características de classificação da rede. Dessa forma, para um algoritmo de retro propagação do erro, o critério de parada procura encontrar um valor mínimo global, os critérios de parada foram ajustados segundo a minimização da função do erro pelo método do gradiente descendente. Como o banco de dados tem um número de amostras expansivas e colapsíveis diferentes, foi usado o índice de perda Erro ao Quadrado Ponderado (WSE) e o algoritmo da rede foi otimizado pelo Método Quase-Newton (QNM), que aponta para o mínimo da função de perda com maior precisão.

$\mathrm{Na}$ última fase de teste, é possível comparar as saídas da rede neural com o conjunto de variáveis independentes a partir da análise dos resultados dos testes: Matriz de Confusão, Métricas de avaliação binária, Gráfico ROC e Gráfico de ganho acumulado, os métodos de teste são definidos a partir do tipo de previsão (aproximação ou classificação). Alcançando resultados aceitáveis para a situação, a rede neural poderá ser generalizada, ou seja, ter seus padrões aplicados às amostras de solos desconhecidos por ela, mas com comportamento conhecido pela literatura, de modo que as previsões possam ser confirmadas.

\section{Avaliação da Exportabilidade do Modelo Pernambucano}

A rede com dados de entrada treinados para Pernambuco cujo desempenho já havia sido avaliado na fase de teste com amostras de solos de Pernambuco, não utilizados para geração do modelo, foi agora aplicada a 45 amostras de solo de outros estados do Nordeste brasileiro, sem nenhum ajuste de peso, a fim de avaliar seu poder de exportação a outras áreas. Cada valor de saída da rede foi comparado aos valores experimentais retirados da bibliografia, para reconhecimento de erro ou acerto, possibilitando uma avaliação do desempenho desta fase denominada validação às cegas (blind test), segundo a metodologia de Amorim (2012). A matriz de confusão, as métricas de avaliação binária, a área sob a curva ROC, o percentual de ganho acumulado e o histograma das populações são calculados, de modo que a confiabilidade na generalização de tais parâmetros de previsão garanta um nível de segurança.

A curva ROC, segundo Amorim (2012), permite tradicionalmente avaliar a qualidade de um classificador binário de modo resumido através da área sob a curva, que em um único número, indica a melhor ou pior qualidade do modelo. Alertando, 
no entanto, para a ideia de que um valor maior nem sempre indica um modelo melhor, pois podemos estar interessados em taxas de verdadeiros positivos (TPR) maiores, mas ao custo de um aumento na taxa de falsos positivos (RPF).

Os critérios estatísticos usados como método para avaliar a capacidade de previsão e de correlações empíricas não foram identificados em literaturas anteriores referentes a mesma temática, entretanto são comuns em análises de redes de classificação, por proporcionarem, a partir do uso de gráficos, uma melhor visualização da multidimensionalidade do problema. O melhor método de estimativa exige critérios em sua seleção, para avaliar as diferentes variáveis de entrada geotécnicas e as diversas composições de banco de amostras disponíveis.

\section{Resultados e Discussão}

Os resultados dos testes aplicados à rede neural com dados de Pernambuco confirmam a correlação existente entre as variáveis de entrada e a característica de expansão ou colapso como verificado anteriormente por Seed, Woodward \& Lundgren (1962) e Chen (1975). A seleção ideal de entradas e de ordem da arquitetura da rede pode ser observada na minimização dos erros a cada iteração, o erro de treinamento representa a capacidade da rede neural de ajustar os dados que ela vê, e o erro de seleção a capacidade da rede neural generalizar para novos dados. A aproximação máxima entre essas linhas indica um ponto mínimo de critério de parada para o treinamento, definindo para essa rede a melhor arquitetura com duas camadas perceptron. $\mathrm{Na}$ Figura 4, a linha azul representa o erro de treinamento e a linha laranja representa o erro de seleção. $\mathrm{O}$ valor inicial do erro de treinamento é 1,9 e o valor final após 14 épocas é 0 . O valor inicial do erro de seleção é 1,9 e o valor final após 14 épocas é 0,47 .

Figura 4 - Histórico dos erros do método Quase-Newton.

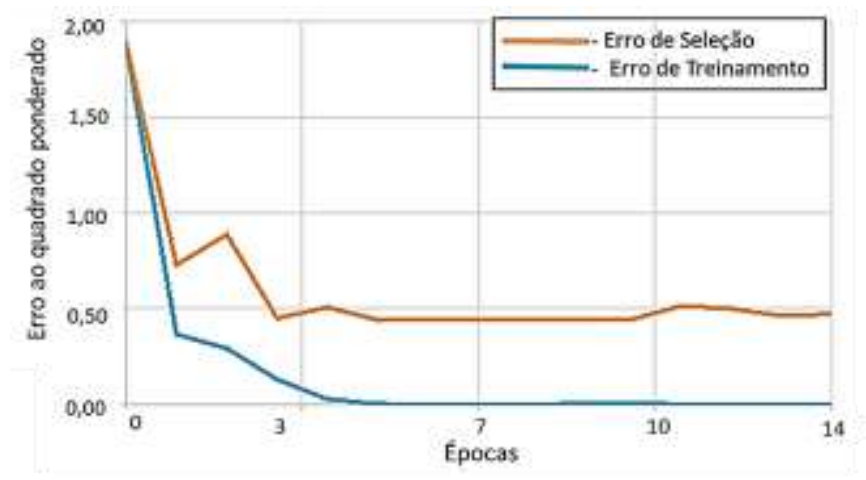

Fonte: Autores (2021).

A análise de desempenho da precisão de previsão da rede, para a fração de amostras destinadas a essa etapa através da matriz de confusão (Tabela 2), mostra que dentre as 17 amostras reservadas para a etapa de teste 13 foram classificadas corretamente $(76,5 \%)$ e quatro amostras classificadas incorretamente $(23,6 \%)$.

Tabela 2 - Matriz de confusão da rede nos pontos de Pernambuco.

\begin{tabular}{ccc}
\cline { 2 - 3 } & Observado Expansivo & Observado Colapsível \\
\hline \multirow{2}{*}{ Previsão de Expansivo } & $6(35,3 \%)$ & $2(11,8 \%)$ \\
& Verdadeiro Expansivo & Falso Expansivo \\
Previsão de Colapsível & $2(11,8 \%)$ & $7(41,2 \%)$ \\
& Falso Colapsível & Verdadeiro Colapsível \\
\hline
\end{tabular}

Fonte: Autores (2021). 
Das quatro amostras classificadas incorretamente, duas têm o solo expansivo classificado como colapsível $(11,8 \%)$ e outras duas $(11,8 \%)$ a situação inversa, solo colapsível previsto como solo expansivo. Nas quatro amostras com erro de classificação foi observada a ausência de informações nas variáveis de entrada, hora duas ausências, hora três ausências das quatro informações de entrada. Fica assim, evidente a importância que as quatro variáveis de entrada têm, perante a identificação dos solos, pois mesmo com bons ajustes de parâmetros, a ausência de quaisquer desses dados compromete, significativamente, a previsão final. As métricas da avaliação binária, decorrentes da matriz de confusão, são apresentadas no Tabela 3.

Tabela 3 - Métricas de Avaliação Binária da rede nos pontos de Pernambuco.

\begin{tabular}{lll}
\hline & Descrição & \% \\
\hline Acurácia & Porção de amostras classificadas corretamente & 76,5 \\
Taxa de erro & Porção de amostras classificadas incorretamente & 23,5 \\
Sensitividade & Porcentagem de solos expansivos previstos como expansivos & 75 \\
Especificidade & Porcentagem de solos colapsíveis previstos como colapsíveis & 77,8 \\
\hline
\end{tabular}

Fonte: Autores (2021).

Segundo as métricas de classificação (precisão da classificação, taxa de erro, sensibilidade e especificidade) podemos concluir que o modelo tem desempenho satisfatório tanto para solos expansivos (sensitividade $=75 \%$ ) quanto para solos colapsíveis (especificidade $=77,78 \%$ ) mesmo para a pequena quantidade de dados disponíveis nas amostras. A diferença de percentuais, embora a quantidade de erros seja a mesma para os dois tipos de solo, se dá pelo fato de haver uma amostra a mais de solo colapsível. A análise gráfica pela curva ROC (Figura 5), apresenta para essa rede uma área sob a curva de 0,819, e um melhor ponto de corte de classificação de 0,719 , ratificando a boa qualidade do classificador, uma vez que um classificador aleatório e representado pela linha diagonal a $45^{\circ} \mathrm{com}$ área sob a curva de 0,5 .

Figura 5 - Gráfico ROC da rede nos pontos de Pernambuco.

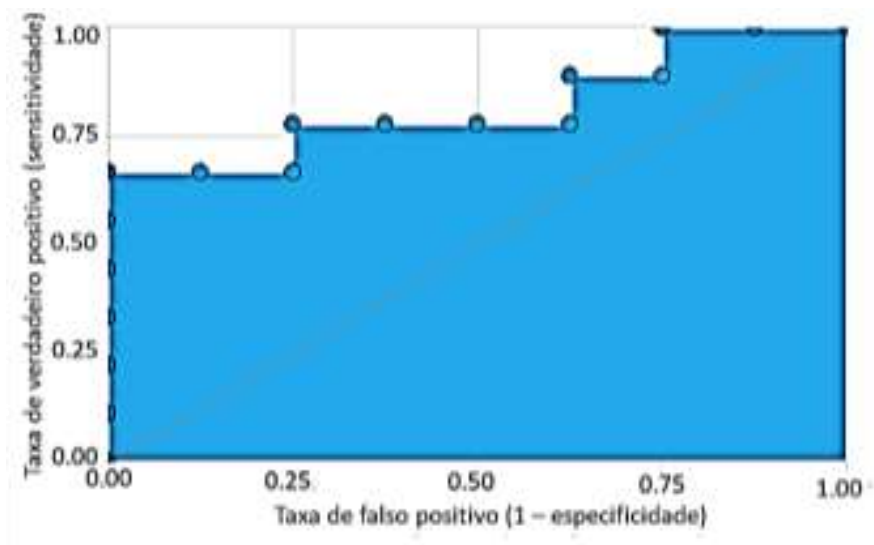

Fonte: Autores (2021).

O ponto ótimo do Gráfico de Ganho Acumulado (Figura 6), onde a porcentagem identificada de amostras de solos expansivos é maximizada e a porcentagem identificada de amostras de solos colapsíveis é minimizada, indica que ao analisar $66 \%$ - de todas as amostras a serem classificadas, $100 \%$ de amostras expansivas já havia sido identificada em detrimento de 30\% de amostras de solo colapsível, característica considerada positiva para o potencial de classificação da rede. 
Figura 6 - Ganho Acumulado da rede nos pontos de Pernambuco.

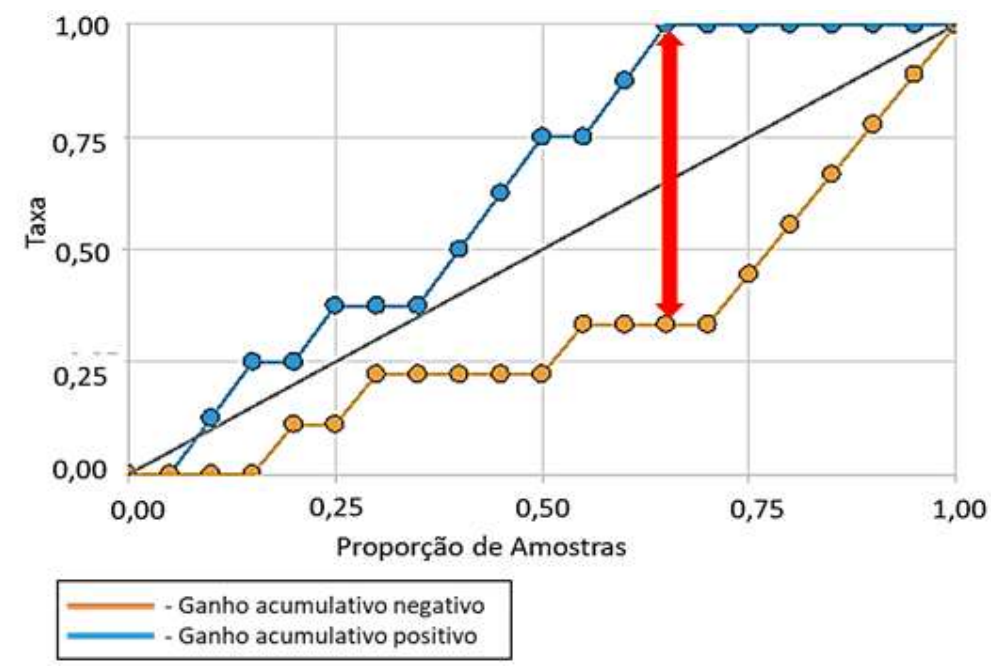

Fonte: Autores (2021).

Ainda analisando o gráfico de Ganho Acumulado, nota-se que ao analisar 50\% das amostras, há uma probabilidade de serem identificadas $75 \%$ de amostras de solo expansivo e $20 \%$ de amostras de solos colapsíveis, enquanto na aleatoriedade, não usando uma rede classificadora, teríamos uma probabilidade de classificar 50\% de amostras de solo expansivo e $50 \%$ de amostras colapsíveis.

A identificação dos valores críticos que melhor representam as variáveis de entrada definem o ponto de referência para a mudança de característica do solo quanto a probabilidade de expansão, para as amostras do banco de dados analisado. Os valores críticos que melhor representam as variáveis de entrada, a qual detalha tais comportamentos observados a partir da curva apresentada, são observados na Figura 7, no caso da variável Fração de Argila temos um ponto crítico situado a 30\%; para a Fração Areia 48\%; para o Índice de Plasticidade 18\%, e finalmente para o índice de Atividade 0,6.

Com isso, é definida a função matemática do modelo de previsão da rede que pode ser usada para previsões em outros programas em uma linguagem e sistema operacional diferente, além de poder ser aplicado a amostras de outras localidades, partindo de um limite de decisão de 0,5 , os quais resultados maiores ou iguais a 0,5 indicam expansão e menos de 0,5 indicam colapsíveis. 
Figura 7 - Valores Críticos da Variável Argila (a), Areia (b), IP (c) e IA (d) para as amostras de solos expansivos.

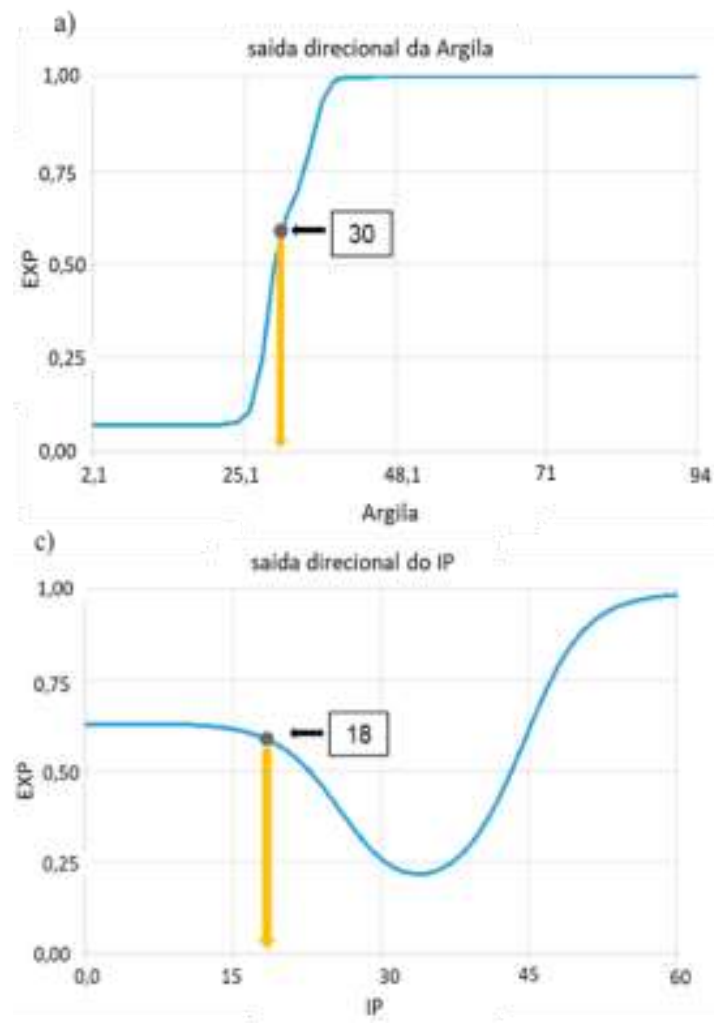

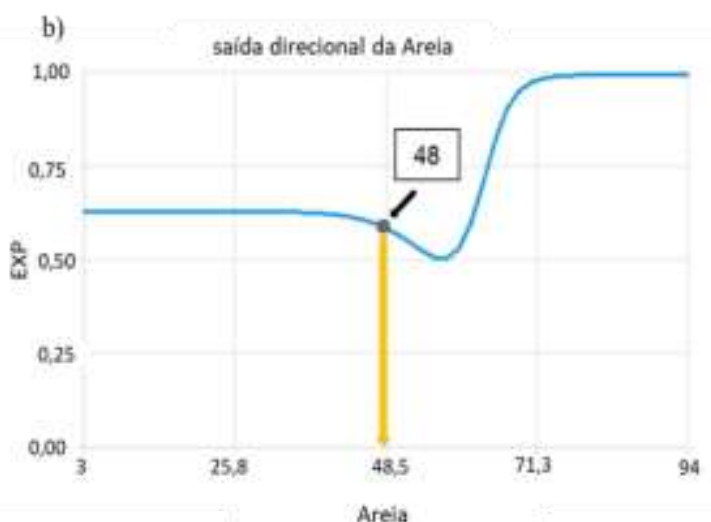

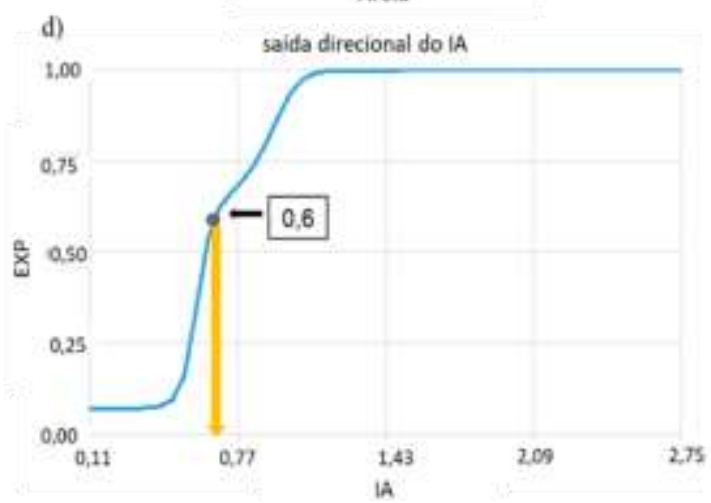

Fonte: Autores (2021).

\section{Resultados da exportação do modelo pernambucano}

De acordo com os resultados obtidos pela generalização da rede a amostras de solo do Nordeste, a matriz de confusão é calculada e os indicadores de avaliação binários são analisados para avaliar a arquitetura implementada, conforme mostrado na Tabela 4 e Tabela 5. Na matriz de confusão, todas as 23 amostras expansivas (51,1\%), e 18 (40\%) amostras de solos colapsíveis foram classificadas corretamente, totalizando uma acurácia de $91,1 \%$. Enquanto quatro $(8,9 \%)$ amostras de solo colapsível foram classificadas erroneamente, assumindo uma taxa de erro de 8,9\%.

Tabela 4 - Matriz de Confusão das amostras de solos dos demais estados do Nordeste.

\begin{tabular}{ccc}
\cline { 2 - 3 } & Observado expansivo & Observado colapsível \\
\hline Previsão de expansivo & $23(51,1 \%)$ & $4(8,9 \%)$ \\
& Verdadeiro Expansivo & Falso Expansivo \\
Previsão de colapsível & $0(0 \%)$ & $18(40 \%)$ \\
& Falso Colapsível & Verdadeiro Colapsível \\
\hline
\end{tabular}

Fonte: Autores (2021).

É necessário atentar que para a correta classificação, todos os dados de entrada sejam definidos, pois como foi visto na etapa de teste, anteriormente, quanto maior a ausência de informação nos registros de entrada das amostras, mais difícil a correta decisão da rede. 
Tabela 5 - Métricas de Avaliação Binária das amostras de solos dos demais estados do Nordeste.

\begin{tabular}{cc}
\hline Métricas & Percentual \\
\hline Acurácia & $91,1 \%$ \\
Taxa de Erro & $8,9 \%$ \\
Sensitividade & $100 \%$ \\
Especificidade & $81,8 \%$ \\
\hline
\end{tabular}

Fonte: Autores (2021).

Houve um aumento das taxas de sensitividade e especificidade diante da comparação com os resultados do teste feito em amostras somente do estado de Pernambuco, isso porque as amostras do Nordeste não apresentaram tantos valores de entrada ausentes como as amostras de Pernambuco favorecendo a classificação da rede. Nessa etapa de validação às cegas, a rede identificou corretamente todas as amostras expansivas (sensitividade 100\%) e classificou erroneamente quatro amostras colapsíveis como expansivas (especificidade 81,8\%). As amostras classificadas incorretamente foram observadas de forma isolada, e foi identificada a ausência de informações de 2 das quatro variáveis solicitadas pela entrada da rede, para uma das amostras; e no caso das outras 3 faltava uma variável de entrada para cada, comprometendo significativamente a capacidade de previsão.

A localização das amostras usadas para validação às cegas da rede neural está apresentada na Figura 8, de modo a destacar a localização das amostras validadas de forma correta e de forma incorreta pela RNA, permitindo a investigação mais profunda a respeito da amostra validada de forma incorreta.

Figura 8 - Localização das 45 amostras de solos dos demais estados do Nordeste classificadas pela RNA.

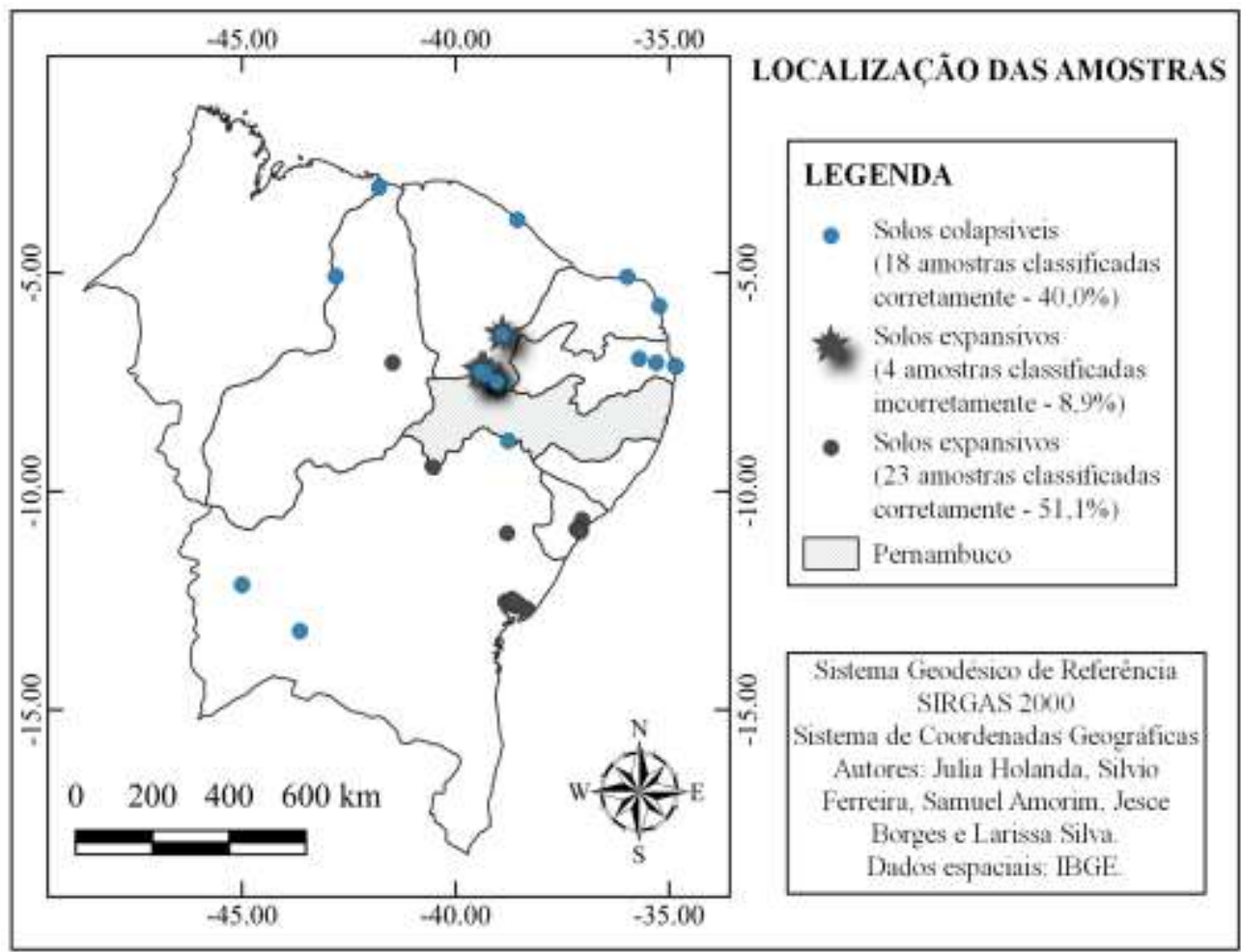

Fonte: Autores (2021). 
Uma das formas de avaliar o desempenho desta etapa é através da curva ROC (Figura 9) de representação bidimensional, que para esse modelo apresentou área sob a curva de 0,948; o que segundo as métricas de classificação, para o caso, ratificam a boa qualidade da rede.

Figura 9 - Gráfico ROC.

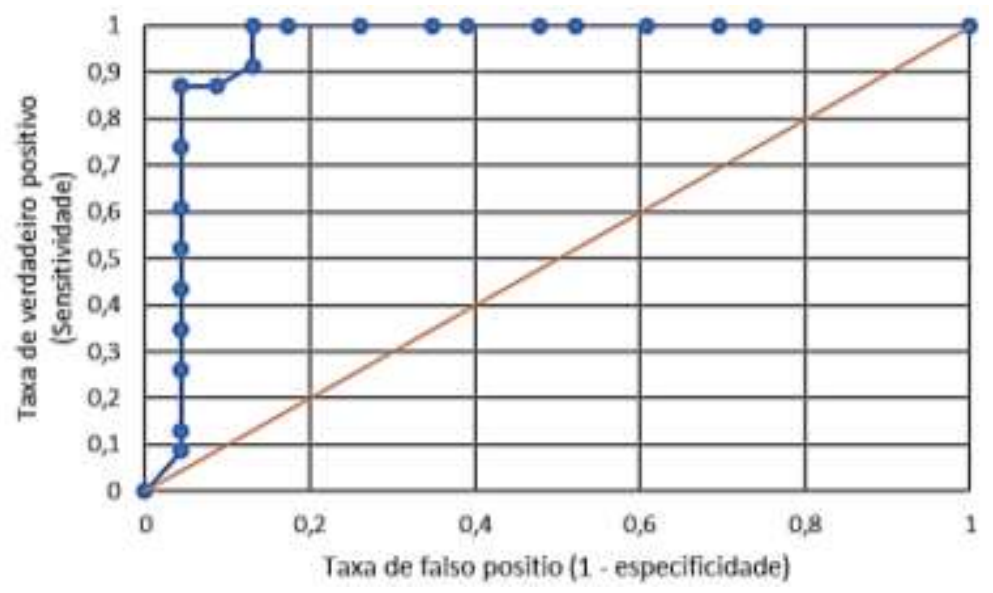

Fonte: Autores (2021).

Também se avaliou a separação das classes ou populações, através do Histograma de População, em uma escala de medição, a posição das amostras testadas com o modelo matemático, e de quanta variação existe entre elas, Figura 10. A característica do bom comportamento da rede é ratificada através do espaçamento definido e pouca mistura (sobreposição) entre as duas populações (colapso e expansão), 18 amostras de colapso foram classificadas corretamente, enquanto 4 amostras de solo colapsível foram classificadas como expansivas. Já as amostras do solo expansivo foram todas classificadas corretamente.

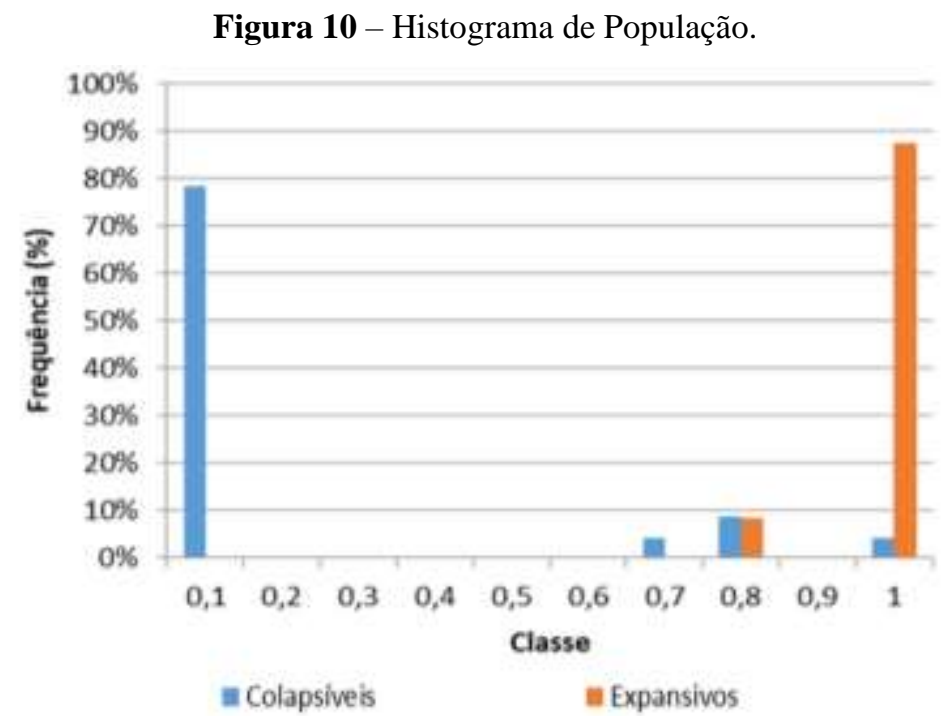

Fonte: Autores (2021).

A partir das observações e comparações feitas nas 45 amostras de outros estados do Nordeste disponíveis para validação às cegas, foi possível confirmar a eficiência de classificação da rede, e sua grande capacidade de exportação. A rede mesmo treinada apenas com amostras de solo de Pernambuco pôde ser exportada para outros estados do Nordeste, e ainda assim classificar corretamente com uma boa margem de precisão e baixo erro. O modelo é representado pelo código descrito abaixo. 
De classificação da rede, tendo como forte característica a exportabilidade através da expressão matemática descrita abaixo. A rede mesmo treinada apenas com amostras de solo de Pernambuco pôde ser exportada para outros estados do Nordeste, e ainda assim classificar corretamente com uma boa margem de precisão e baixo erro.

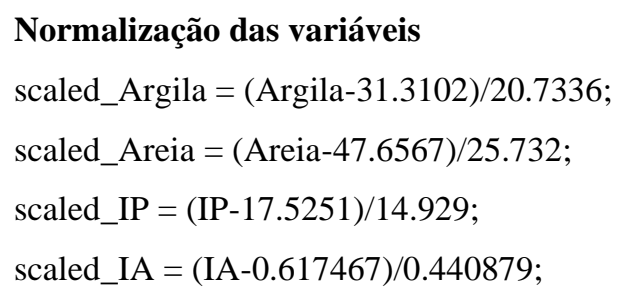

\section{Equações das funções logísticas e probabilísticas}

$\operatorname{logistic}(\mathrm{x})\{$ return $1 /(1+\exp (-\mathrm{x}))\}$

$\operatorname{probability}(\mathrm{x})\{$ if $\mathrm{x}<0$

return 0

else if $x>1$

return 1

else

return $\mathrm{x}\}$

\section{Equação da RNA}

y_1_1 = Logistic $(1.64231+($ scaled_Argila*7.71703)+(scaled_Areia*-3.81293)+

(scaled_IP*3.83541)+(scaled_IA*4.1356));

non_probabilistic_EXP $=$ Logistic $\left(-2.98875+\left(\mathrm{y} \_1 \_1 * 6.58936\right)\right)$;

$\mathrm{EXP}=$ probability (non_probabilistic_EXP)

\section{Conclusão}

O modelo da rede neural proposta apresenta-se como um instrumento promissor e válido, auxiliando na resolução de problemas complexos ainda não totalmente compreendidos, como nesse caso, a identificação de solos expansivos e colapsíveis em amostras de solos de Pernambuco, e com aplicação dos padrões às amostras do Nordeste brasileiro.

A melhor arquitetura de rede neural, constituída a partir de 87 amostras de solo do estado de Pernambuco, conta com quatro variáveis Geotécnicas de entrada e uma variável de saída as quais possuem boas correlações entre si, que permitem identificar um conjunto de valores críticos da caracterização físicas dos solos com maior probabilidade de ser expansivo tais como: fração de argila > 30\%; fração areia < 48\%; índice de plasticidade > 18\%, e índice de atividade > 0,6.

A taxa de acurácia para a rede desenvolvida com amostras de Pernambuco é 76,5\% e em sua aplicação às amostras dos demais estados do Nordeste houve um reconhecimento ainda maior desses padrões, alcançando uma acurácia de $91,1 \%$, comprovando a capacidade de considerar os dados dos solos de Pernambuco para captar a tendência do movimento de expansão da superfície do solo em outros Estados.

Pretende-se no futuro implementar uma rede neural artificial treinada com dados de solos de todas as regiões do Brasil, mantendo as variáveis de entrada apresentadas nessa pesquisa, de modo a favorecer ainda mais a análise via rede neural pela robustez da rede. 


\section{Agradecimentos}

Agradecemos ao CNPq pelo apoio ao desenvolvimento da pesquisa Processo: 421087 / 2018-8.

\section{Referências}

Amorim, S. F. (2012). Estudio comparativo de métodos para la evaluación de la susceptibilidad del terreno a la formación de deslizamientos superficiales: Aplicación al Pirineo Oriental. Tesis Doctoral, Universitat Politecnica de Catalunya. Barcelona, Espanã.

Ashayeri, I., \& Yasrebi, S. (2009). Free-swell and swelling pressure of unsaturated compacted clays; experiments and neural networks modeling. Geotechnical and Geological Engineering. 27 (1), 137-153.

Bandeira, A. P. N., Souza Neto, J. B., \& Rolim, J. I. D. (2017). Recalque por colapso do solo e suas manifestações Patológicas. In: XIII Congresso Internacional sobre Patologia e Reabilitação de Estruturas, 303-318. Crato, Brasil.

Basma, A. A., Barakat, S. A., \& Omar, M. (2003). Modeling time dependent swell of clays using sequential artificial neural networks. Environmental and Engineering Geoscience, 9 (3), 279-288.

Chitero, J. G. M., Bonini Neto, A., Bonini, C. dos S. B., Heinrichs, R., Soares Filho, C. V., Mateus, G. P., Bisi, B. S., Costa, N. R., Piazentin, J. C., Meirelles, G. C., \& Gabriel Filho, L. R. A. (2020). Analysis of the physical recovery of degraded soils via Artificial Neural Networks using a graphical interface. Research, Society and Development, 9 (7), p. e257973719. https://doi.org/10.33448/rsd-v9i7.3719.

Chen, F. H. (1975). Fundation on Expansive Soils. Amsterdam: Elsevier.

Daksanamurty, V., \& Raman, V. (1973). A simple method of identifying an expansive soil. Soils and Foundation, 13(1), 97-104.

Doris, J. J., Rizzo, M. M., \& Dewoolkar, M. M. (2008). Forecasting vertical ground surface movement from shrinking/swelling soils with artificial neural networks. Int. J. Numer. Anal. Meth. Geomech, 32, 1229-1245. https://doi.org/10.1002/nag.666.

Driscoll, R., \& Crilly, M. (2000). Subsidence damage to domestic buildings: Lessons learned and questions asked. London: Building Research Establishment.

Ferreira, S. R. M. (1990). Banco de Dados de Solos Especiais - Colapsíveis do Estado de Pernambuco. In: IX Congresso Brasileiro de Mecânica dos Solos e Engenharia de Fundações, 2, 81-86. Salvador, Brasil.

Paiva, S. C., Freitas, M. L. A. A., Barbosa, R., Rego, W. A., \& Ferreira, S. R. M. F. (2012). Estabilização de Solos Expansivos de Cabrobó, Paulista e Suape/PE com Cal. In: XVI Congresso Brasileiro de Mecânica dos Solos e Engenharia Geotecnica, p.264. Porto de Galinhas, Brasil.

Ferreira, S. R. M., \& Ferreira, M. G. V. X. (2009). Mudanças de volume devido à variação de teor de umidade em um Vertisolo no Semi-Árido de Pernambuco. Revista Brasileira de Ciência do Solo (Impresso), 33, 779-791.

Gitirana Junior, G. F. N., Camapum de Carvalho, J., Ferreira, S. R. M., \& Mascarenha, M. M. A. (2012). O comportamento de solos não saturados submetidos à infiltração. In: Carvalho, J. C., Gitirana Junior, G. F. N., \& Carvalho, E. T. L. (Org). Tópicos sobre infiltração: teoria e prática aplicadas a solos tropicais, 157-180. Brasília, Brasil: Faculdade de Tecnologia.

Haykin, S. (1994). Neural Networks: A Comprehensive Foundation. New York: Prentice-Hall.

Ikizler, S. B., Aytekin, M., Vekli, M., \& Kocabas, F. (2010). Prediction of swelling pressures of expansive soils using artificial neural networks. Advances in Engineering Software, 41(4), 647-655.

Jucá, J. F. T., Gusmão Filho, J. A., \& Justino da Silva, J. M. (1992). Laboratory and field tests on an expansive soil in Brazil. In: 7th International Conference on Expansive Soils, 1, 337-342. Dallas, Texas.

Merouane, F. Z., \& Mamoune, S. M. (2018). Prediction of Swelling Parameters of Two Clayey Soils from Algeria Using Artificial Neural Networks. Mathematical Modelling in Civil Engineering, 14(3), 11-26. https://doi.org/10.2478/mmce-2018-0008.

Moosavi, M., Yazdanpanah, M. J., \& Doostmohammadi, R. (2006). Modeling the cyclic swelling pressure of mudrock using artificial neural networks. Eng. Geol., 87, 178-194.

Nakashima, C. H., Saito, L. A., \& Hella, M. (2014). Análise da estabilização de solo expansivo em plataforma ferroviária. Trabalho de Conclusão de Curso (Graduação), Universidade Tecnológica Federal do Paraná. Curitiba, Brasil.

Nelson, J. D., \& Miller, D. J. (1992). Expansive soils: problems and practice in foundation and pavement engineering. New York: John Wiley \& Sons.

Paiva, S. C., Assis, M. A. A., Ferreira, M. G. V. X., \& Ferreira, S. R. M. (2016). Propriedades geotécnicas de um solo expansivo tratado com cal. Revista Matéria, 21(2), 437-440.

Pereira, A. S., Shitsuka, D. M., Parreira, F. J., \& Shitsuka, R. (2018). Metodologia da pesquisa científica. [eBook]. Santa Maria. Ed. UAB / NTE / UFSM. https://repositorio.ufsm.br/bitstream/handle/1/15824/Lic_Computacao_Metodologia-Pesquisa-Cientifica.pdf?sequence=1 .

Pessoa, A. D., Sousa, G. C. L., Araujo, R. C., \& Anjos, G. J. M. (2021). Artificial neural network model for predicting load capacity of driven piles. Research, Society and Development, 10 (1), p. e12210111526. https://doi.org/10.33448/rsd-v10i1.11526.

Prechelt, L. (1997). Investigation of the CasCor Family of Learning Algorithms. Neural Netw, 10(5), 885-896. https://doi.org/10.1016/S0893-6080(96)001153. 
Research, Society and Development, v. 10, n. 15, e110101522541, 2021

(CC BY 4.0) | ISSN 2525-3409 | DOI: http://dx.doi.org/10.33448/rsd-v10i15.22541

Rodrigues, R. A., \& Vilar, O. M. (2013). Colapso de solo desencadeado pela elevação do nível d'água. Revista Nacional de Gerenciamento de Cidades, 1(6), $13-27$.

Seed, H. B., Woodward, D. J., \& Lundgren, R. (1962). Prediction for compacted clays. Journal soil machanics and Fundations division, 88(3), 53-87.

Simmes, P. R. M., \& Costa Filho, L. M. (1981). Características mineralógicas de solos expansivos do Recôncavo Baiano. In: Simpósio Brasileiro de Solos Tropicais, 569-588. Rio de Janeiro, Brasil.

Simões de Oliveira, A. G. S., Jesus, A. C., \& Miranda, S. B. (2006). Estudo geológico geotécnico dos solos expansivos da região do Recôncavo Baiano. In: Simpósio brasileiro de jovens geotécnicos, 2. Nova Friburgo, Brasil.

Skempton, A. W. (1953). The colloidal activity of clays. In: Proceedings of the International Conference on Soil Mechanics on Foundation Engeneering, 1(3), 587-595. London, England.

Sobral, H. S. (1956). Contribuição ao estudo de Massapê como solo para construção. Tese para Cátedra de Materiais de Construção, Universidade Federal da Bahia, Escola de Belas Artes. Salvador, Brasil.

Suleiman, G. K. A., Tapahuasco, W. F. C., \& Neto, R. G. S. (2013). A Utilização da Cal em Forma de Pasta como Agente Estabilizante em Solos Oriundos da Cidade de Alegrete/RS. In: VII Seminário de Engenharia geotécnica do Rio Grande de Sul, 74-80. Santa Maria, Brasil.

Teixeira, C. Z. (1998). Solos Colapsíveis: Um Problema Para a Engenharia de Fundações. In: $27^{\circ}$ Congresso Brasileiro de Engenharia Agrícola. Poços de Caldas, Brasil.

Van der Merve, D. H. (1964). The Prediction of heave from the plasticity index and percentage clay fraction of soils: The Civil Engeneer. South African Institute of Civil Engineers, 6, 103-107.

Vargas, M. (1981). Introdução à mecânica dos solos. São Paulo: McGraw-Hill do Brasil. 